\title{
The Diploma of the Faculty of Sexual and Reproductive Healthcare: an innovative new training programme
}

\author{
Jenny Heathcote, Chris Wilkinson
}

\section{Introduction}

The Diploma of the Faculty of Sexual and Reproductive Healthcare (DFSRH) is considered to be the gold standard for training in sexual and reproductive health (SRH). Educationalists are realising the potential of using elearning technologies to support learner-centred training programmes in line with 21 st century models of learning, teaching and assessment, and the Faculty has been working with the Department of Health's e-Learning for Health (e$\mathrm{LfH}$ ) team to develop an innovative new training programme with online access to the theoretical components of the curriculum. This is part of a blended learning package that will enable clinicians to acquire the knowledge and skills they need to manage community sexual and reproductive health consultations.

DFSRH training prior to January 2010 required trainees to go on a Faculty recognised 3-4-day theory course; they then attended SRH clinics for competency-based training and assessments. This involved a significant time commitment from trainees and trainers. The new programme provides greater flexibility in terms of delivery, and trainees can draw on their clinical experience in other areas of work to meet their learning objectives.

Learning pathway and assessment process Trainees are encouraged to take their DFSRH at an appropriate stage in their career training. The entry requirements for the course include proficiency in basic consultation skills and gynaecological experience so that they can perform a pelvic and speculum examination, and know how cervical cytology samples are taken. This may be achieved during a hospital placement or an attachment in general practice.

The learning pathway progresses from theory to clinical practice (Figure 1). The learning, teaching, assessment and evaluation components of the programme are all closely interlinked (i.e. there is structural alignment ${ }^{1}$ within the programme). Trainees are encouraged to engage in learning activities that are likely to result in their acquiring the necessary skills and knowledge required to pass the assessments, which in turn are designed to demonstrate whether the learning objectives of the diploma have been met.

Assessment is a key part of any postgraduate qualification. The overall value of any assessment may be evaluated by examining its 'utility index' ${ }^{2}$ which looks at reliability, validity, educational impact, cost and

\section{J Fam Plann Reprod Health Care 2010; 36(2): 65-68}

Faculty of Sexual and Reproductive Healthcare (FSRH), London and Cheshire East Community Health, Waters Green Medical Centre, Macclesfield, UK

Jenny Heathcote, FFSRH, MA, Chair of General Training Committee, FSRH; and Associate Specialist, Sexual Health

Faculty of Sexual and Reproductive Healthcare, London and Margaret Pyke Centre, London, UK

Chris Wilkinson, MBBS, FFSRH, e-SRH, Clinical Lead; and Lead Consultant

Correspondence to: Dr Jenny Heathcote, Waters Green Medical Centre, Sunderland Street, Macclesfield SK11 6JL, UK. E-mail: j.heathcote@nhs.net acceptability. A further category, feasibility, was added in the Postgraduate Medical Education and Training Board (PMETB) guidance on developing and maintaining an assessment system. ${ }^{3}$

Consistency and reproducibility of results impact on reliability. A variety of assessment techniques are used for the DFSRH; guidance for those making assessments ensures a standardised approach - the training programme is supported by documentation for trainers and assessors that make the assessment goals explicit. Guidance notes for trainees specify standards, describe the assessment tools, and define progression and opportunities for reassessment. (These are available on the Faculty website at www.fsrh.org).

Validity requires a tool to test what it is supposed to test: in this case whether a clinician is able to manage community SRH consultations. In an authentic assessment process learning should be integrally related to the understanding and solution of real-life problems. ${ }^{4}$ Two new tools for workbased assessment have been developed, drawing on the literature in medical education and experience of the mini CEX (Clinical Evaluation Exercise) and case-based discussion tools developed by other specialties. 5,6

The Assessment of Clinical Practice (ACP) is based on observation of the trainee during a SRH consultation. Trainees are encouraged to include experience they gain in consultations where they have not been directly observed, and some consultations may be assessed by a Reflection and Discussion of Clinical Practice (RDCP). The ACP and RDCP are structured assessment tools specifically written to achieve the learning aims of the DFSRH, with feedback from the trainer as a key component.

Educational impact assumes that assessment drives the learning that underpins training. Observation of 'real-life' consultations is part of the formative, as well as the summative, assessment of the DFSRH. There has been recent interest in the development of work-based formative assessment to encourage observation of clinical practice. ${ }^{7}$ Feedback is an essential part of the education and assessment process and can have a very powerful effect on learning; 8 this is emphasised throughout the Diploma.

Cost, acceptability and feasibility have been important factors in the design; free online access to the e-SRH enables trainees to consolidate and assess their theoretical knowledge early in the programme. The Course of 5 can be run over a day or as five individual sessions spread over time. Providing opportunities to practise skills on the Course of 5 will ensure that trainees will be well prepared to lead a SRH consultation when they start their clinical experience.

\section{Theory: e-learning (e-SRH)}

The development of the e-learning component represents a major advance in standardising training, knowledge and clinical care. e-SRH is a joint venture between e-LfH and the Faculty of Sexual and Reproductive Healthcare (FSRH). Whilst the concept for e-SRH was as part of medical training, the Faculty is fully aware of the value of this e-SRH as part of training for other professional groups. The content of e-SRH is informed by current UK guidance, which includes FSRH, National Institute for Health and Clinical Excellence (NICE) and British Association for Sexual Health and HIV (BASHH) guidance. 


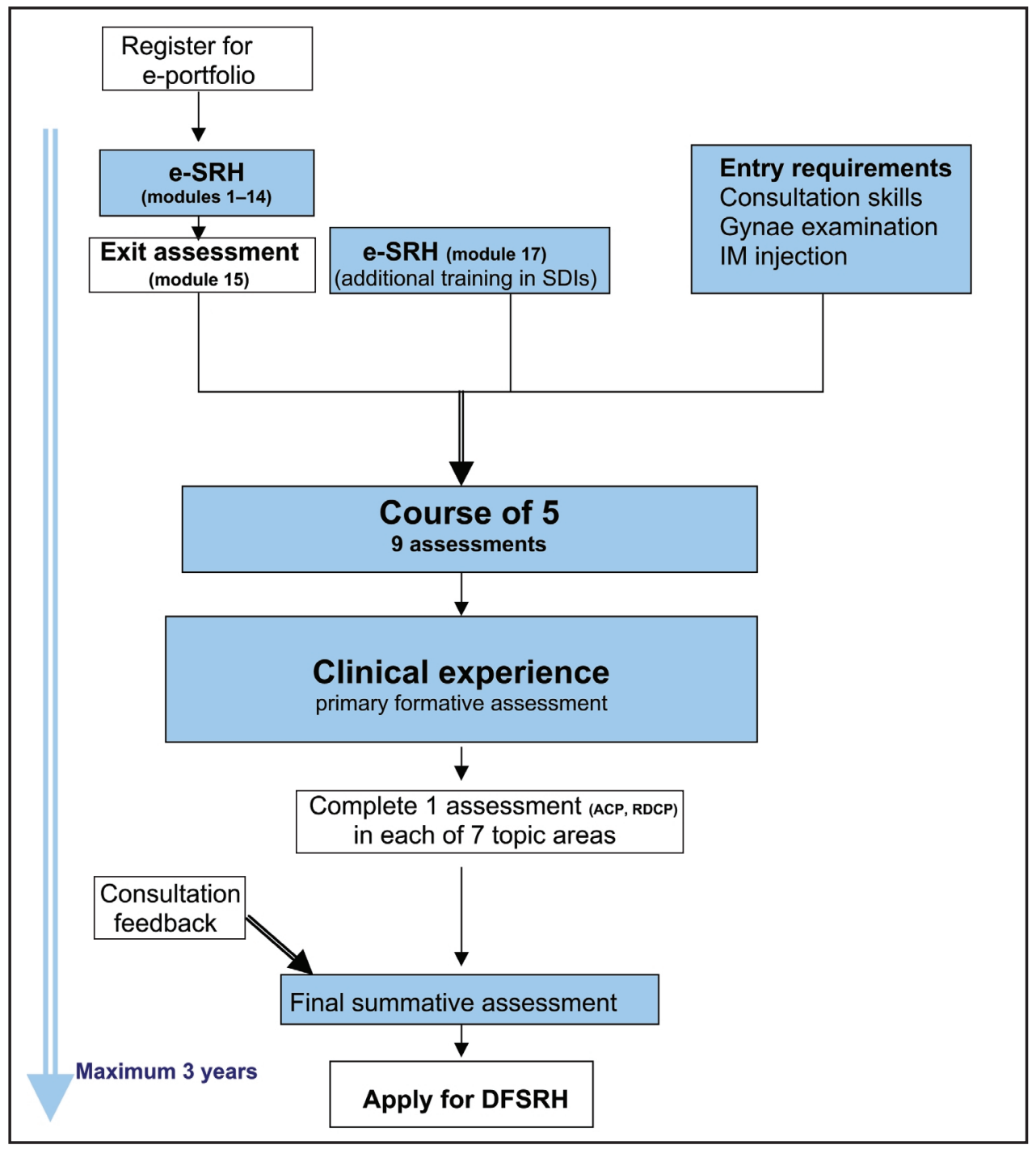

Figure 1 Learning pathway leading to the Diploma of the Faculty of Sexual and Reproductive Healthcare (DFSRH) qualification. ACP, Assessment of Clinical Practice; IM intramuscular; RDCP, Reflection and Discussion of Clinical Practice; SDI, subdermal implant

e-SRH is organised in a series of modules delivering the theory component for the DFSRH and the Faculty Letters of Competence in Subdermal Implants (LoC SDI) and Intrauterine Techniques (LoC IUT). The modules comprise several sessions, each one of which is planned to take 20 minutes to complete (in total, 50 hours of training has been developed). The 14 basic modules are compulsory for those taking the Diploma.

A deliberate and concerted effort was made to ensure that the module editors and authors of the sessions comprised a mix of frontline clinicians (doctors and nurses) working in the field of SRH, whether that be in general practice or specialist services. Some of the sexually transmitted infection (STI) sessions were developed by BASHH. Each of the authors worked closely with an Instructional Designer (ID). The IDs have a role that involves editing, planning the use of multimedia and interactivity, and putting the various components of a session into a standardised format. They also have to work with other IDs to ensure consistency across the project. The IDs had to gain a great deal of knowledge about the subject in order to be effective in their role. In simplistic terms, this process could be viewed as taking a lecture comprising of a presentation and verbal communication, and turning it into an educationally sound e-learning session.

Although appearing quite different, sessions have a consistent core structure comprising:

- Title and summary of the session.

- Learning objectives for the session. There are usually no more than five objectives. The learning objectives were developed for each session by breaking down the curriculum key knowledge points and then prioritising them; from this the learning objectives were written.

- Prerequisites to be completed before starting the session. This ensures that the learner is prepared for the session and should have any relevant background knowledge that is required to enable them to compete the session successfully. This also links sessions to that knowledge is learned in a given order, each stage building on the one before.

- Session content. This is the information-giving part of the session. This is done in a variety of ways including written text, animations, video, clinical cases, knowledge checks and feedback.

- Self-assessment. This comprises short assessments based on the learning objectives; on completing each question, feedback is given which includes explanatory notes. This feedback is an essential part of e-learning as it enables learners to judge for themselves whether or not they have achieved the outcome of the lesson and whether they need to review parts of the session again. The scores achieved in the self-assessments within the sessions are not stored.

- Additional reading or resources. These are optional but point the learner in the right direction should they wish to read around the subject. Links to further reading and references are deliberately not included within the session content to ensure that the learner keeps focused on the session itself. 
e-learning programmes vary in the level of interactivity with tutors and other students. At this point in time, e-SRH has no formal facility for such communication but this may be considered in the future. However, trainers could work with their trainees from before they start e-SRH if they wish. Even without this contact, e-SRH is learner-focused in that learners can work at their own pace, and review or repeat specific sections as required and/or if they want to create their own learning path through the sessions.

In developing e-SRH there was much debate over whether or not to have a compulsory, marked assessment to be taken on completing all the sessions. There are compelling arguments in both directions. The final, 15th module, is comprised of 60 questions taken from the sessions. At present, only the learner will see the marks they achieve for this exercise. However, over the next year it is planned to expand the bank of questions and to test them to see how well they perform as discriminating assessments of knowledge, with a view to a more formal assessment.

The content will be reviewed on an annual basis and developed. There is also the ability to make more rapid changes where these are required. For some, the work on e$\mathrm{SRH}$ is over, but for others it has just begun.

\section{Course of 5}

Following completion of the e-SRH, the Course of 5 is a series of five 1-hour sessions with standardised content, delivered in small groups (four trainees or fewer). This provides an opportunity to apply theoretical knowledge to clinical scenarios, to explore personal attitudes and to demonstrate some practical skills such as model arm training for subdermal implants. An assessment component enables competent trainees to progress to $\mathrm{SRH}$ clinical experience.

\section{Clinical experience and assessments}

The clinical experience is an opportunity to put the theory and skills from the e-SRH and Course of 5 into clinical practice, and to assess when the trainee has achieved the level required for independent practice in community SRH. The primary trainer and trainee meet for an initial formative assessment to develop the trainee's personal learning plan to achieve the desired outcome.

During the development of the training programme, seven clinical scenarios were identified as being at the core of community SRH.

1 An effective contraception choices consultation.

2 A consultation with a woman wishing to use an oral or injectable contraceptive, patch or vaginal ring.

3 Assessing and advising a woman wishing to use an intrauterine method or subdermal implant, prior to insertion.

4 Responding to a request for emergency contraception.

5 Taking an appropriate history and assessment of a woman with bleeding problems whilst using a hormonal method.

6 Taking an appropriate sexual history and risk assessment for STI and pregnancy, and performing the appropriate tests for an asymptomatic woman or man requesting sexual health screening.

7 Taking an appropriate history and assessment of a woman with vaginal discharge or pelvic pain.

Final summative assessments using the ACP or RDCP tools are required in each core area to demonstrate that the trainee has achieved the level of competency required for independent practice.

The DFSRH clinical experience translates sexual health theory into clinical practice; participation of SRH service users is implicit. Over the last few years, the National
Health Service has made great strides towards fully engaging people in the design and delivery of services. They are routinely asked for their views about their experience of services, and to contribute to staff training. 9 Research in family planning clinics ${ }^{10}$ showed a high level of altruism amongst patients who were keen to be involved in DFSRH training; asking for their feedback after a consultation with a trainee facilitates triangulation of evidence from client, trainee and trainer. Consultation feedback is reviewed throughout clinical training, and is part of the summative assessment for the Diploma, which is undertaken with the primary trainer, once satisfactory assessments in the seven core topics have been completed.

\section{e-portfolio}

The use of e-portfolios to support medical education programmes has grown rapidly; more than 20 versions used by over 35000 UK healthcare trainees have been developed by NHS Education Scotland (NES). The Faculty has worked with NES to develop a bespoke e-portfolio for the DFSRH and the Faculty LoC SDI and LoC IUT.

The DFSRH e-portfolio is much more than an online record of progress and assessments; it is a learning tool, personally managed and owned by the trainee who can selectively share their experience of formal and informal learning activities with their trainers. It provides a managed environment for reflective learning and enables the trainee to plan, set and record learning objectives as part of their personal development plan.

\section{Training package for trainers}

It is essential that those who will be involved in delivering this new programme are fully prepared and trained in the delivery of the various components. A package of resources and materials has been designed to support 'training the trainers'. This includes a sample programme for a training day, with a presentation by an educationalist that describes the basic educational principles underpinning the programme, annotated PowerPoint ${ }^{\mathrm{TM}}$ presentations, suggestions for small group work, and the resources required to run a workshop to look at how an ACP assessment might be made during a consultation, and ways in which a trainer might provide feedback to a trainee. This package has been designed for training groups of trainers, but could be used by individuals as a tool to support selfdirected learning in educational techniques.

\section{Summary}

The new DFSRH training programme is an exciting development in medical education. It embraces modern technological advances and educational theories to support the training of the next generation of clinicians to manage community SRH consultations.

\section{Acknowledgements}

The General Training Committee of the Faculty (which oversees the DFSRH) acknowledges the support received from many individuals, and particularly the involvement of diplomates and trainers who responded to requests for their views during the development of the programme.

Representatives from the British Association for Sexual Health and HIV, the Royal College of General Practitioners and the Associate Members Group on the General Training Committee all contributed to the work.

Educational support for the clinical components provided by Cathy Sherratt, Senior Lecturer in Clinical Education, Edge Hill University was invaluable.

The course material was reviewed from a consumer's perspective by Toni Belfield.

Kenneth Hardy-Smith led the team from e-Learning for Health (e-LfH) and Alex Haig from NHS Education Scotland (NES) led the e-portfolio development. 
Chris Wilkinson was the clinical lead for the e-SRH, and Jenny Heathcote was the clinical lead for the clinical components (Course of $5 /$ clinical experience and assessments).

\section{Statements on funding and competing interests \\ Funding None identified.}

Competing interests None identified.

\section{References}

1 Biggs J. What the student does: teaching for enhanced learning. Higher Education Research and Development 1999; 18: $57-75$

2 van der Vleuten CPM. The assessment of professional competence: developments, research and practical implications. Adv Health Sci Educ Theory Pract 1996; 1: 46-67.

3 Postgraduate Medical Education and Training Board (PMETB) Guidance. Developing and Maintaining an Assessment System - A PMETB Guide to Good Practice. January 2007. http://www.pmetb.org.uk/fileadmin/user/QA/Assessment/Asses sment_system_guidance_0107.pdf [Accessed 1 February 2010].
4 Swanson DB, Norman GR, Linn RL. Performance-based assessment: lessons from the health professions. Educational Researcher 1995; 24(5): 5-11, 35.

5 Intercollegiate Surgical Curriculum Programme. Workplace based assessments. https://www.iscp.ac.uk/Assessment/WBA/ Intro.aspx [Accessed 1 February 2010].

6 Royal College of Paediatrics and Child Health. http://www.rcpch.ac.uk/doc.aspx?id_Resource $=3385$ [Accessed 26 February 2010].

7 Norcinii JJ, Burch VC. Workplace-based Assessment as an Educational Tool (AMEE Guide 31). Dundee, UK: Association for Medical Education in Europe, 2008.

8 Norcini J. The power of feedback. Med Educ 2010; 44: 16-17.

9 Department of Health. Public and patient experience and engagement. http://www.dh.gov.uk/en/Managingyour organisation/PatientAndPublicinvolvement/index.htm [Accessed 1 February 2010].

10 Heathcote J. What motivates patients to become involved in postgraduate medical training in a family planning clinic? J Fam Plann Reprod Health Care 2008; 34: 103-106.

\section{JOURNAL REVIEWS}

\section{Qualitative research to capture patients' views}

\section{Introduction}

Over the last decade there has been a growing emphasis on the importance of incorporating the views and perceptions of patients or, more generally, service users in health and social care. Qualitative methods often feature as a useful approach to measuring such views. The Journal of Family Planning and Reproductive Health Care is of course not a novice to qualitative approaches, since it has published a series of introductory articles on qualitative methods. ${ }^{1-5}$ This journal review considers three very recent publications in the British Medical Journal, each paper focusing on slightly different aspects of qualitative methods to measure patients' views. ${ }^{6-8}$

\section{Serial qualitative interviews}

The first paper highlights that although face-toface interviews may provide us with a large amount of in-depth information, it can be very much a snapshot of a patient's experiences. ${ }^{6}$ The authors from the University of Edinburgh argue that interviewing a patient at different points during their illness can help to (a) build rapport and develop trust between the interviewer and the interviewee and hence bring out more personal and sensitive issues and (b) capture patients' changing experiences of the disease, their condition and service use. Murray et al. discuss a number of potential issues in serial interviewing, such as when to recruit and when and where to conduct the initial and subsequent interviews, as well as the dropout of interviewees over time and ethical considerations.

The second methods paper by the same research team outlines multi-perspective qualitative interviews, whereby two or more people are interviewed as a set or case study. ${ }^{7}$ This approach attempts to capture complementary as well as contradictory perspectives in people who are in some sort of a relationship with the central interviewee (often the patient). For example, the pivotal interviewee in a study of in vitro fertilisation (IVF) failure would be the women undergoing treatment, but interviewing so-called significant others such as her partner and the IVF treatment midwife may offer greater insight into the woman's perspective. As Kendall and colleagues suggest, multi-perspective interviews can help us understand the relationships and dynamics among patients, their families, carers and service providers, and the different perspectives of each of these interviewees on the situation. Some readers may know the multi-perspective interviewing approach by its subset of couple interviewing.

The third paper appraises qualitative research methods as used alongside randomised controlled trials (RCTs) of complex health care interventions. ${ }^{9}$ Lewin et al. found that only 30 out of 100 trials had a qualitative element, but in twothirds of these trials there was no attempt to integrate the qualitative and quantitative findings, neither in the analysis nor the overall interpretation. The authors conclude that qualitative studies alongside RCTs are still fairly uncommon. The trials that used qualitative methods used these prior to the trial or during the trials, but very few studies used qualitative methods to help explain trial results.

\section{Conclusions}

The first two papers highlighted specific useful ways of applying qualitative methods when eliciting patients' views and perspectives. The authors outline the methods' strengths and, to a lesser extent, their weaknesses for both serial interviewing and multi-perspective interviewing. 6,7 Both papers show what health care researchers can learn from the social and behavioural sciences where qualitative approaches are much more widely used. The third paper offers a more global view on qualitative methods, namely when used alongside RCTs of complex health care interventions. This paper concludes that qualitative methods are making only slow inroads into the more traditional research methods designed to test and generate evidence-based health care interventions. ${ }^{9}$ It is obvious that there is still a long way to go before we make the best possible use of qualitative research methods in health and health care research

\section{Edwin van Teijlingen, MEd, $\mathrm{PhD}$}

Medical Sociologist/Professor of Maternal and Perinatal Health Research, School of Health \& Social Care, Bournemouth

University, Bournemouth, UK.

E-mail:vanteijlingen@bournemouth.ac.uk

References

van Teijlingen ER, Forrest $\mathrm{K}$. The range of qualitative research methods in family planning and reproductive health care, J Fam Plann Reprod Health Care 2004; 30: $171-173$.

2 Forrest Keenan K, van Teijlingen ER. The quality of qualitative research in family planning and reproductive health care, J Fam Plann Reprod Health Care 2004; 30: 257-259.

3 Forrest Keenan K, van Teijlingen E, Pitchforth E. The analysis of qualitative research data in family planning and reproductive health care. J Fam Plann Reprod Health Care 2005; 31: 40-43.

4 Pitchforth E, Porter M, van Teijlingen ER, Forrest Keenan $\mathrm{K}$. Writing up and presenting qualitative research in family planning and reproductive health care. J Fam Plann Reprod Health Care 2005; 31 132-135.

5 van Teijlingen ER, Pitchforth E. Focus group research in family planning and reproductive health care, J Fam Plann Reprod Health Care 2006; 32: 30-32.

6 Murray SA, Kendall M, Carduff E, Worth A, Harris FM, Lloyd $A$, et al. Use of serial qualitative interviews to understand patients' evolving experiences and needs. BMJ 2009; 339: 958-960.

Kendall M, Murray SA, Carduff E, Worth A, Harris F, Lloyd $A$, et al. Use of multiperspective qualitative interviews to understand patients' and carers' beliefs, experiences, and needs. BMJ 2010; 240: 196-199.

Lewin S, Glenton C, Oxman AD. Use of qualitative methods alongside randomised controlled trials of complex healthcare interventions: methodological study. BMJ 2009; 339: b3496.

\section{JOURNAL REVIEW WRITERS}

The Journal regularly reviews articles from related publications and is looking to recruit more volunteers to compile these short reviews. For further information and/or to offer your services (at most once or twice a year) please e-mail your contact details to the Journal Editorial Office together with a note of any special interests and/or expertise to assist us in allocating relevant articles to individual reviewers. For further information on this role please contact the Journal Editorial Office at journal@fsrh.org. 